\title{
Tracking coherent structures in a regional ocean model with wavelet analysis: Application to Cape Basin eddies
}

\author{
A. M. Doglioli, ${ }^{1,2}$ B. Blanke, ${ }^{1}$ S. Speich, ${ }^{1}$ and G. Lapeyre ${ }^{3}$ \\ Received 13 October 2006; revised 20 December 2006; accepted 29 January 2007; published 23 May 2007. \\ [1] This study is mainly aimed at proposing objective tools for the identification and \\ tracking of three-dimensional eddy structures. It is conducted with a high-resolution \\ numerical model of the ocean region around South Africa, and emphasis is put on \\ Cape Basin anticyclones and cyclones thought to be actively implicated in the \\ Indian-Atlantic interocean exchange. We settle on wavelet analysis for the decomposition \\ and processing of successive maps of relative vorticity for a simulation run with $\frac{1}{10}^{\circ}$ \\ resolution. The identification of three-dimensional coherent structures comes with the \\ calculation of eddy trajectories and the time evolution of eddy properties. Instantaneous \\ mass transport and momentum of eddies are calculated from the knowledge of \\ instantaneous drift velocities, volumes, and diameters. The success of the regional model \\ and of the analysis technique is assessed through comparisons with equivalent \\ observations.
}

Citation: Doglioli, A. M., B. Blanke, S. Speich, and G. Lapeyre (2007), Tracking coherent structures in a regional ocean model with wavelet analysis: Application to Cape Basin eddies, J. Geophys. Res., 112, C05043, doi:10.1029/2006JC003952.

\section{Introduction}

[2] The Agulhas Current is the most intense western boundary current of the world ocean, and its retroflection shows one of the highest signals in eddy kinetic energy. Mesoscale eddies and large current rings pinch off from the Agulhas Retroflection and are usually associated with an Indian Ocean water leakage to the Atlantic Ocean [Gordon, 2003; Richardson et al., 2003]. Satellite measurements in this area allow eddy tracking from sea surface height (SSH) anomalies [e.g., van Ballegooyen et al., 1994; Goñi et al., 1997; Arhan et al., 1999]. Eddy trajectories can be reconstructed from successive surface elevation maps and coupled with in situ observations during concomitant cruises [e.g., Garzoli and Goñi, 2000]. As pointed out by Morrow et al. [2004], altimetry defines a robust way to track propagating features provided that their typical scales are correctly sampled both in time and space by remote sensing. However, gaps in knowledge of the full three-dimensional identity of anticyclones and cyclones can obstruct more accurate diagnostics like the mass transport achieved by the eddy field. In this respect, numerical experiments are often fruitful. A primitive equation model of the Atlantic circulation allowed Treguier et al. [2003] to

\footnotetext{
${ }^{1}$ Laboratoire de Physique des Océans, UMR 6523 CNRS/IFREMER/ UBO, Brest, France.

${ }^{2}$ Now at Laboratoire d'Océanographie et de Biogéochimie, UMR 6535 CNRS/Université de la Méditerranée, OSU/Centre d'Océanologie de Marseille, Marseille, France.

${ }^{3}$ Laboratoire de Météorologie Dynamique IPSL, École Normale Supérieure/CNRS, Paris, France.

Copyright 2007 by the American Geophysical Union. 0148-0227/07/2006JC003952
}

define Agulhas eddies from $\mathrm{SSH}$ anomalies with respect to a time mean. More recently, but for another oceanic region, Penven et al. [2005] developed an algorithm based on the calculation of the Okubo-Weiss parameter to systematize the process of eddy tracking in the Peru Current System. Indeed, Okubo [1970] and Weiss [1991] derived a criterion to separate flows into hyperbolic regions, where strain dominates, and elliptic ones, where vorticity dominates. This criterion has been widely used to analyze numerical simulations of two-dimensional turbulence (McWilliams [1984]; Elhmaidi et al. [1993], among others). However, as pointed out by Basdevant and Philipovitch [1994], the validity of the criterion key assumption is restricted to the core of the vortices, i.e., the strongest elliptic regions of the flow. The Okubo-Weiss criterion is therefore not fully appropriate for a decomposition of a flow into background and eddy components.

[3] The identification technique developed throughout this study is based on the wavelet analysis of modeled relative vorticity. Wavelets form an efficient basis set for localized structures such as ocean eddies. The main advantage of wavelets compared to Fourier transforms is that the former give information about a function or data set with respect to scale and location in contrast to the latter, which provide a one-parameter family of coefficients representing the global frequency content. For the ocean, Jameson and Miyama [2000] applied wavelet analysis to the numerical resolution of Kelvin and Rossby waves. Luo and Jameson [2002] presented an application of wavelet analysis to timeevolving structures such as eddies and fronts described by numerical modeling or by satellite data. In fluid dynamics, both for numerical simulations and laboratory experiments 

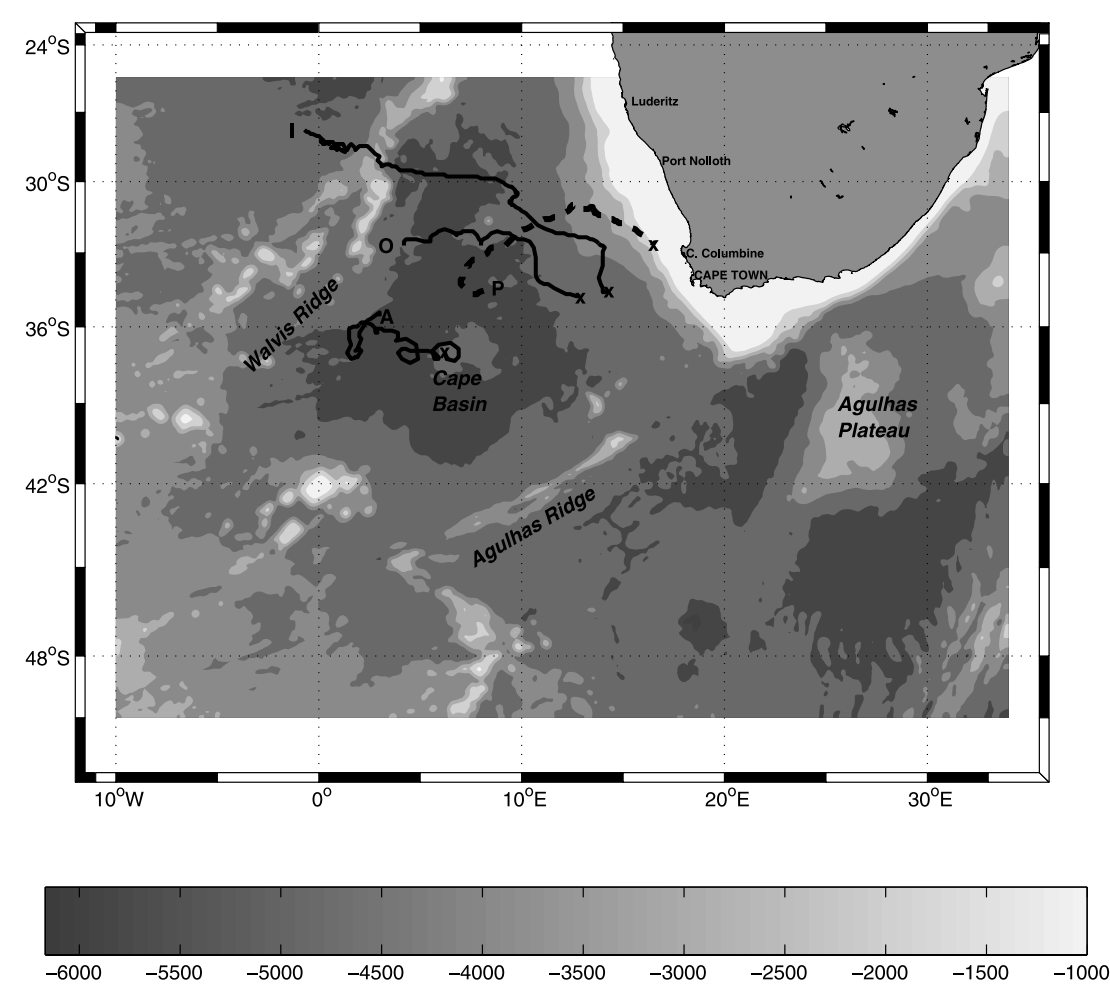

Figure 1. Model domain and bathymetry (m). The trajectories of three anticyclones (solid lines) and one cyclone (dashed line) are drawn in black. Cross symbols and letters indicate the beginning and end of each trajectory, respectively. $\mathrm{P}=$ Panoramix, $\mathrm{I}=$ Idefix, $\mathrm{O}=$ Obelix, $\mathrm{A}=$ Asterix, see section 3 for nomenclature.

[Ruppert-Felsot et al., 2005; Siegel and Weiss, 1997, and references therein], the coherent and incoherent background components of a turbulent flow have been separated with a wavelet-based decomposition of the relative vorticity field. These successful applications drove us to apply the wavelet analysis technique used in two-dimensional turbulence to the identification of eddies within horizontal slices of modeled relative vorticity. Then, in order to capture and track the full three-dimensional envelope of each eddy, we developed an original and simple algorithm based on superimposing structures at different instants and different vertical levels.

[4] Recently, Boebel et al. [2003] reviewed the theories proposed in the literature for the Indo-Atlantic interocean exchange. They limited the concept of "isolated Agulhas Rings embedded in a sluggish Benguela Drift" to the northwestern Cape Basin and called "Cape Cauldron" the southeastern Cape Basin, where mesoscale cyclone/ anticyclone interactions result in vigorous stirring and mixing. This region is very appropriate as a field of study to test our technique with the aim to propose new clues to open questions about the role of oceanic mesoscale eddies. Our discussion is mainly devoted to four eddies, i.e., three anticyclones and one cyclone, obtained in a high-resolution numerical simulation of the ocean dynamics around southern Africa. Section 2 describes the ocean model, whereas section 3 reports on the method we developed to identify three-dimensional coherent structures and follow them as a function of time. In section 4, these structures are compared with those observed in the area under study, and then, we introduce some parameters useful for eddy characterization. Our conclusions are drawn in section 5 .

\section{Ocean Model}

[5] Our circulation model is based on the IRD (Institut de Recherche pour le Développement) version of the Regional Ocean Modeling System (ROMS). The reader is referred to the work of Shchepetkin and McWilliams [2003, 2005] for a more complete description of the numerical code. The model domain extends from $10^{\circ} \mathrm{W}$ to $34^{\circ} \mathrm{E}$ and from $50^{\circ}$ to $25.4^{\circ} \mathrm{S}$ (Figure 1). Its grid, forcing, initial, and boundary conditions were built with the ROMSTOOLS package [P. Penven et al., ROMSTOOLS: A series of tools for the pre- and postprocessing of oceanic regional ROMS simulations, submitted to Ocean Modelling, 2007. http://www.brest.ird.fr/ Roms tools]. The model grid is $441 \times 317$ points with a resolution of $\frac{1}{10}^{\circ}$ corresponding to $9 \mathrm{~km}$ in mean grid spacing, which allows a correct sampling of the first baroclinic Rossby radius of deformation throughout the whole area (about $30 \mathrm{~km}$ according to Chelton et al. [1998]). The horizontal grid is isotropic with no introduction of asymmetry in the horizontal dissipation of turbulence. It therefore provides a fair representation of mesoscale dynamics. The model has 32 vertical levels, and the vertical $s$ coordinate is stretched for boundary layer resolution. The bottom topography is derived from a $2^{\prime}$ resolution database [Smith and Sandwell, 1997]. Although a numerical scheme associated with a specific equation of state limits errors in the computation of the horizontal pressure gradient [Shchepetkin and McWilliams, 2003], the bathymetry field $h$ must be filtered to 


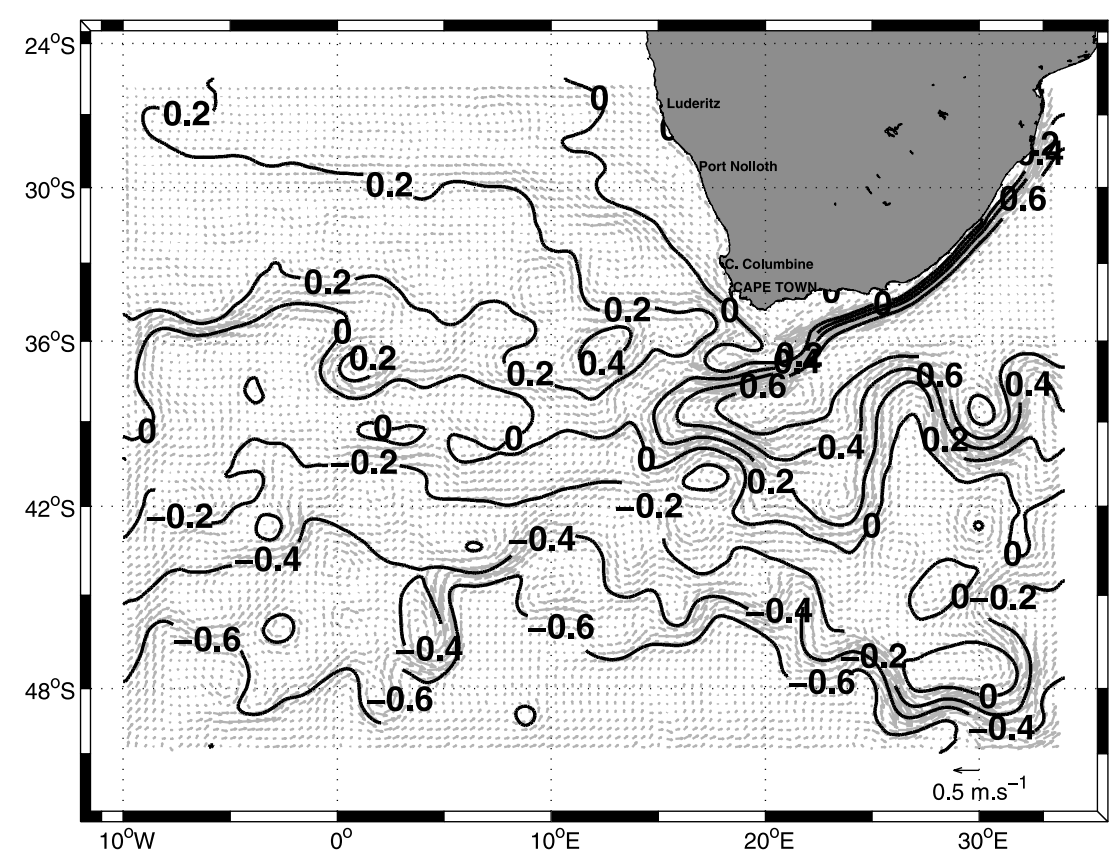

Figure 2. Model-climatology. Contour lines and arrows show the SSH anomaly (m) and barotropic current $\left(\mathrm{m} \mathrm{s}^{-1}\right)$, respectively.

keep the slope parameter $r$ as $r=\frac{\nabla h}{2 h} \leq 0.3$ [Beckmann and Haidvogel, 1993]. All the model external forcings are derived from climatologies. At the surface, the heat and fresh water fluxes introduced in the model are extracted from the Comprehensive Ocean-Atmosphere Data Set (COADS) [Da Silva et al., 1994]. For the wind stress, a monthly mean climatology is computed from QuikSCAT satellite scatterometer data gridded at $\frac{1}{2}^{\circ}$ resolution [Liu et al., 1998]. The contrast in resolution between the thermodynamical and dynamical atmospheric fields gives more weight to the dynamical forcing of the region [Capet et al., 2004; Blanke et al., 2005]. At the four lateral boundaries facing the open ocean, the model solution is connected to the surroundings by an active, implicit, and upstream-biased radiation condition [Marchesiello et al., 2001]. Under inflow conditions, the solution at the boundary is nudged toward temperature-, salinity-, and geostrophic velocity-fields calculated from Levitus [1998] climatology (NODCWOA98 data provided by the NOAA/OAR/ESRL PSD, Boulder, Colorado, USA, from their Web site at http://www.cdc.noaa.gov/), which is also used for the initial state of the model. The geostrophic velocity is referenced to the $2000 \mathrm{dbar}$ level. The width of the nudging border is $150 \mathrm{~km}$, and the maximum viscosity value for the sponge layer is set to $1000 \mathrm{~m}^{2} \mathrm{~s}^{-1}$.

[6] We run an 11-year simulation with model outputs averaged and stored every 2 days of simulation. Figure 2 shows the model climatology of SSH and barotropic velocity obtained, averaging these fields over the last 8 years of simulation. We find a fair agreement between simulated and observed circulation patterns [Richardson et al., 2003, Figure 5]. A narrow and intense Agulhas Current flows along the eastern coast of Africa and eventually retroflects between $15^{\circ}$ and $20^{\circ} \mathrm{E}$. In addition to the good reproduction of the meandering structure of the Agulhas Return Current, the simulation highlights the development of a high-level mesoscale activity characterized by the generation of
Agulhas rings, anticyclones and cyclones, filaments, and meanders (for example, Figures 3 and 4). The vigorous stirring and mixing processes observed by Boebel et al. [2003] in the so-called Cape Cauldron are well simulated. The model reproduces shear-edge cyclonic eddies in the bight of Agulhas Bank in good agreement with observed features [e.g., Penven et al., 2001; Lutjeharms et al., 2003]. Moreover, through a recent analysis of the same simulation, Doglioli et al. [2006] diagnosed an Indo-Atlantic interocean exchange of intensity comparable with the one inferred from observations.

\section{Eddy Identification and Tracking}

[7] From the Wavelab library (http://www-stat.stanford. edu/wavelab/), we developed a set of MATLAB routines to analyze the circulation calculated by the ocean model. Our procedure can be decomposed into the three following steps: wavelet analysis, time tracking, and vertical tracking.

\subsection{Wavelet Analysis}

[8] The wavelet analysis consists in the decomposition of a signal under study into orthogonal, multiresolution wave packets in a way similar to a Fourier decomposition. Such a technique allows efficient data compression of various signals such as images or sounds. A wave packet is a square integrable modulated waveform well localized in both position and wave number. Since such a method was applied in the past to the extraction of eddies in twodimensional turbulence [Siegel and Weiss, 1997], the reader is referred to this paper for a thorough discussion about the pertinence and details of the wavelet transform. Here the wave packets are used to decompose successive horizontal maps of relative vorticity and to extract localized structures in space. We also choose the Haar basis, which is an orthonormal basis of $L^{2}\left(R^{2}\right)$ [Daubechies, 1988, 1992]. 

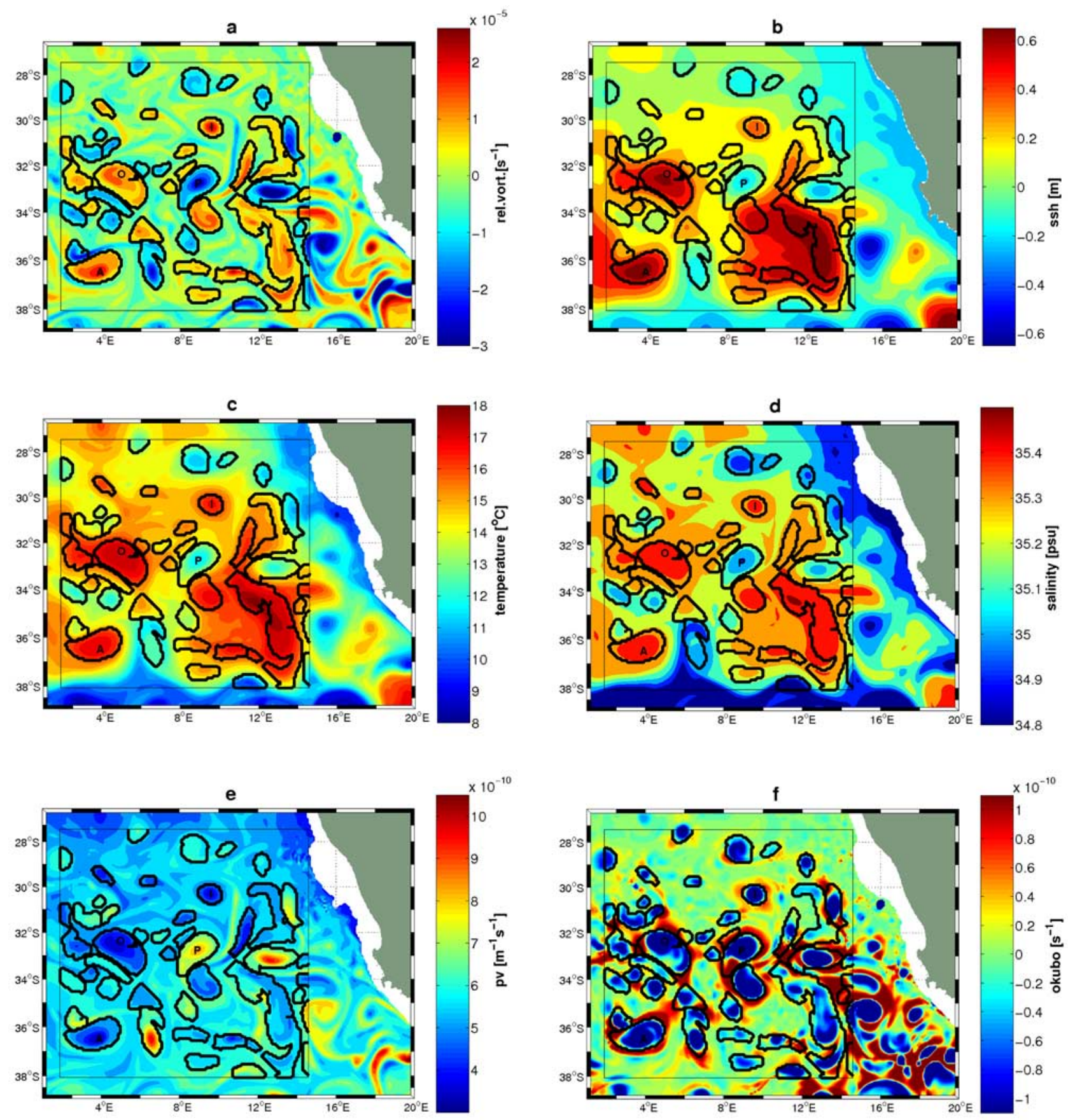

Figure 3. Wavelet analysis. (a) Shaded colors represent relative vorticity $\left(\mathrm{s}^{-1}\right)$, (b) SSH anomaly (m), (c) temperature $\left({ }^{\circ} \mathrm{C}\right)$, (d) salinity (psu), (e) potential vorticity $\left(\mathrm{m}^{-1} \mathrm{~s}^{-1}\right)$, and (f) Okubo-Weiss criterion $\left(\mathrm{s}^{-1}\right)$. All fields are calculated on day $11 /$ month 3/year 7 and, except SSH, at depth $-200 \mathrm{~m}$. The black square shows the $256 \times 256$ grid point domain of the wavelet analysis applied on relative vorticity, and the identified eddies are contoured in black. Letters A, O, I, and P indicate anticyclones Asterix, Obelix, and Idefix and cyclone Panoramix, respectively.

The algorithm in use has four different substeps as follows: At first, a best basis is found to minimize a cost function (here the Shannon entropy) [Wickerhauser, 1994; Coifman and Wickerhauser, 1992]; this basis varies with each time step under consideration and allows one to find the best location for the wave packets. Second, the model relative vorticity is expanded on this basis. Third, the wavelets are sorted out as a function of their wavelet coefficients.
Only the wavelets with the largest coefficients are kept. The number of coefficients that are kept depends on the dimension of the basis computed using the Shannon entropy (usually $10 \%$ of the initial set of wavelets). The method acts as pattern recognition since the reconstructed signal is zero wherever there is no identified pattern. Four, the structures are extracted one after the other by searching first the maximum of the vorticity modulus, then by 

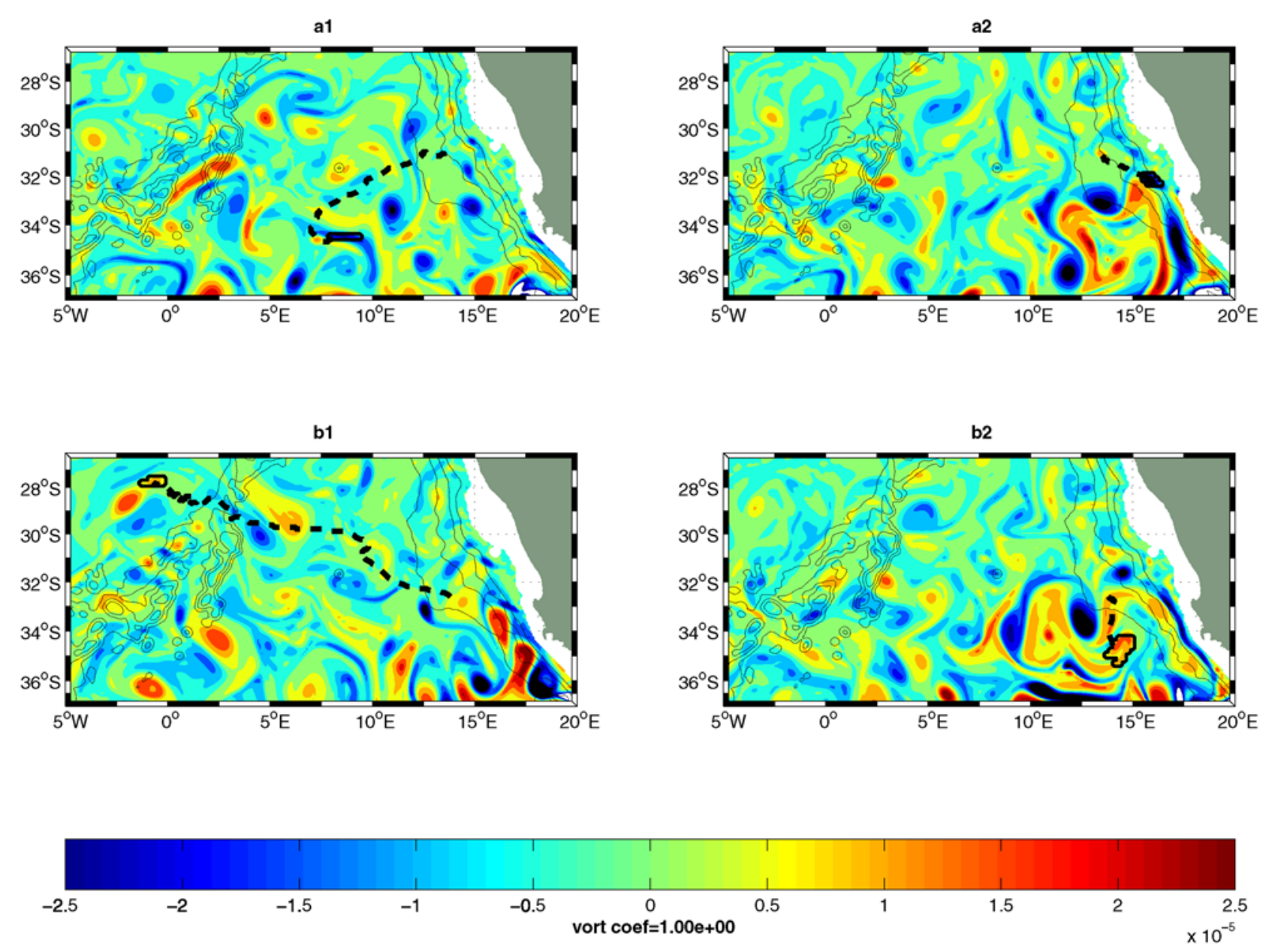

Figure 4. "Death" (left panels) and "birth" (right panels) of cyclone Panoramix (upper panels) and anticyclone Idefix (lower panels). Eddy patterns are shown by black and thick solid lines. Forward (left panels) and backward in time (right panels) trajectory segments are drawn with black and thick dashed lines. Bathymetry is shown in black and thin solid contours $(-1000,-2000,-3000,-4000 \mathrm{~m})$. (a1) Relative vorticity $\left(\mathrm{s}^{-1}\right)$ is shown in color at times day $14 /$ month $5 /$ year 7 , (a2) day $10 /$ month $11 /$ year 6, (b1) day 11/month 10/year 7 and (b2) day 3/month 12/year 6 .

spreading the structure in each direction in space till finding a minimum in vorticity. At last, we merge together adjacent structures with more than six gridcell edges in common, and we eliminate filamentary patterns by ignoring structures less than four grid point wide. The resulting localized structures that cover more than 30 model gridcells, i.e., roughly $2500 \mathrm{~km}^{2}$, are kept and used to separate and define eddies.

[9] Processing relative vorticity with a wavelet-based decomposition gives excellent results in terms of eddy identification (as already shown by Ruppert-Felsot et al. [2005]). Relative vorticity tends to overemphasize frontal structures since it intensifies with the vertical motions that develop in oceanic fronts [Wang, 1993]. This quantity is therefore suitable for eddy edge detection. It also reveals small-scale filaments that can be easily removed because of their elongated shape and small coverage area. Moreover, relative vorticity is free from large-scale gradients unlike Ertel potential vorticity, which incorporates the $\beta$ effect and is sensitive to large-scale spatial density gradients. Equivalent gradients are also present in temperature, salinity, and
$\mathrm{SSH}$. On the other hand, the use of relative vorticity does not require the somewhat arbitrary definition of a reference field to calculate anomalies. Last, the Okubo-Weiss parameter lies on an assumption that restricts eddy detection to eddy cores [Basdevant and Philipovitch, 1994]. Its use would prevent an efficient decomposition between background and eddy signals.

[10] We performed several tests to optimize the parameters involved in the first step of our analysis. It turns out that the critical parameter is the number of spectral coefficients kept for signal reconstruction. Our best results are obtained with a percentage of about 9 to $11 \%$. Figure 3 shows an example of results issued from our analysis. The $256 \times$ 256-grid point domain spans the region to the northwest of the Agulhas retroflection. The relative vorticity map (Figure $3 \mathrm{a}$ ) is calculated at $-200 \mathrm{~m}$ on day $11 /$ month $3 /$ year 7. Among the 44 identified structures, some patterns look like filaments or meanders, but most of them are well-defined eddies. The following discussion will focus on (1) the cyclone at $33^{\circ} \mathrm{S}, 9^{\circ} \mathrm{E}$ (letter $\mathrm{P}$, hereafter referred to as Panoramix), (2) the anticyclone at $30^{\circ} \mathrm{S}, 10^{\circ} \mathrm{E}$ (letter I, hereafter 
referred to as Idefix), (3) the anticyclone at $32^{\circ} \mathrm{S}, 5^{\circ} \mathrm{E}$ (letter $\mathrm{O}$, hereafter referred to as Obelix), and (4) the anticyclone at $36^{\circ} \mathrm{S}, 4^{\circ} \mathrm{E}$ (letter $\mathrm{A}$, hereafter referred to as Asterix). The eddy signal is also clearly present in SSH (Figure $3 \mathrm{~b}$ ). The wavelet-based eddy contours fit well with the negative anomaly induced by cyclone Panoramix (contour $-0.1 \mathrm{~m}$ ) and with the positive anomalies of anticyclones Idefix, Obelix, and Asterix (contours $+0.3,+0.4$, and $+0.5 \mathrm{~m}$, respectively). SSH captures only the large-scale patterns of the eddy field because it is related to the baroclinic stream function characterized by weak gradients at the eddy periphery. Patterns in temperature (Figure 3c) and salinity (Figure 3d) at depth $200 \mathrm{~m}$ are also in good agreement with the wavelet analysis for the cyclone (colder and fresher than surrounding water) and anticyclones (warmer and saltier). This is true for most of the eddies except for some discrepancies likely due to the presence of a large-scale salinity and temperature gradient superimposed on the eddy signature. A better eddy identification based on temperature or salinity fields would require the removal of a mean climatological component. The comparison of the wavelet analysis with the Ertel potential vorticity at $-200 \mathrm{~m}$ (Figure $3 \mathrm{e}$ ) confirms that our technique is able to correctly detect the whole eddy area. Identified cyclones (anticyclones) precisely overlap with the contours of $7(5) \times 10^{-10} \mathrm{~m}^{-1} \mathrm{~s}^{-1}$. The Okubo-Weiss criterion was also tested for comparison (Figure $3 \mathrm{f}$ ). In this field, the cores of the vortices correspond to the strongest elliptic regions (where vorticity dominates strain) and are characterized by strongly negative values of the parameter. However, our analysis is somewhat better since it gives eddy contours close to the structure shown by the Ertel potential vorticity. The Okubo-Weiss criterion characterizes only the inner core of the eddies.

[11] At the end of this step, each identified structure is numbered, and its area $A$ is measured. The eddy center is defined as the grid point of local maximum of absolute relative vorticity over the eddy area $A$ with a precision corresponding to the model grid spacing. Let us define the diameter $D$ as the average of the zonal $\left(D^{\mathrm{EW}}\right)$ and meridional $\left(D^{\mathrm{NS}}\right)$ cords that intercept each eddy center with both endpoints on the edge of the structure (defined through the wavelet analysis). This definition accounts for stretched shapes.

\subsection{Time Tracking}

[12] Tracking identified eddies forward in time requires that the following criterion be satisfied:

$$
c_{t, z=-200} \in \mathcal{E}_{t-\Delta t, z=-200}
$$

where $c_{t, z=-200} \equiv(i c, j c)_{t, z}=-200$ is the eddy center at the time $t$ and depth $-200 \mathrm{~m}$ and $\mathcal{E}_{t-\Delta t}$ is the set of grid points of the same eddy at the previous time step. The sampling period of the model output, $\Delta t=2$ days, was proven by several tests to cause no bias in the analysis (data not shown). The translational velocity of the eddy is calculated as the distance covered by the eddy center over successive 2-day intervals. At each time step of the analysis, the instantaneous translational velocity $v$ and the diameter $D$ of each coherent eddy are both recorded. As criterion (1) can be easily adapted for backward time tracking, we checked that both tracking directions led to very comparable results.
Thus an eddy identified at a specific instant is tracked both backward and forward in time until criterion (1) cannot be satisfied, which stops the analysis. The last instants of the forward and backward trackings are considered as the "death" and "birth" of the eddy, respectively. Figure 4 shows eddy contours and surrounding relative vorticity at the end of Panoramix and Idefix time trackings. Cyclone Panoramix stops when it becomes an elongated filament of negative vorticity (Figure 4a1), whereas its backward time tracking shows its formation on the continental slope near Cape Columbine (Figure 4a2). Anticyclone Idefix is followed forward in time until it merges with a larger anticyclone to the north of Walvis Ridge (Figure 4b1) and backward in time till it detaches itself from a large anticyclonic structure under pressure from a cyclone moving southwestward (Figure 4b2).

\subsection{Vertical Tracking}

[13] The analysis is repeated at several depths to diagnose the vertical extent of an eddy identified at first at $-200 \mathrm{~m}$. The analysis is started at this depth to eliminate the model surface layers liable to be affected by a dynamics that is too sensitive to air-sea interactions. Let us state that a structure identified at the level $z$ belongs to an eddy already identified at the level $z-\Delta z$ on condition to satisfy criterion (2):

$$
c_{z} \in \mathcal{E}_{z-\Delta z}
$$

where $c_{z} \equiv(i c, j c)_{z}$ is the center of the structure identified at the level $z$ and $\mathcal{E}_{z-\Delta z}$ is the set of grid points of the selected eddy at the level $z-\Delta z$. After sensitivity tests and computing time considerations, we set the distance between two successive horizontal slices to $\Delta z=100 \mathrm{~m}$. The vertical tracking ends at depth $i z_{L}$ just before the eddy signal in relative vorticity becomes too weak to be detected. In order to avoid an excessive vertical extent of eddies, our vertical tracking was stopped at $z_{\max }=-1000 \mathrm{~m}$ (see Figure 5). This maximum depth matches the vertical extent of Agulhas rings that are usually found in field measurements [Garzoli et al., 1999; Schmid et al., 2003] and numerical models [Donners et al., 2004].

[14] We also checked that the vertical extent found for the eddies was in agreement with a maximum depth based on the criterion by Flierl [1981]. It is worth noting that, with this criterion, an eddy can be tracked with depth as long as its rotational speed exceeds its translation speed. We calculated the rotational speed of our eddies by averaging the tangential velocity at the ends of both diameters $D^{\mathrm{EW}}$ and $D^{\mathrm{NS}}$, and we defined their translation speed $v$ as in section 3.2. After computation of the deepest immersion at which the criterion by Flierl [1981] could be satisfied (hereafter $z_{\text {Flierl }}$, this parameter was considered as undefined when it approached the local ocean floor by less than $1000 \mathrm{~m}$. Figure 5 exhibits smooth evolutions of $z_{\text {Flierl }}$ and $i z_{L}$ for cyclone Panoramix (upper panel) and anticyclone Idefix (bottom panel) except on the occasion of sudden deepenings for brief periods. These events happen mostly when the translational velocity of the eddy decreases and the upper $1000 \mathrm{~m}$ of the structure are able to spin up movements in the layers underneath. Indeed, van Aken et al. [2003] showed that an Agulhas ring rotating with relatively intense kinetic energy can extend down to the ocean bottom. In our 

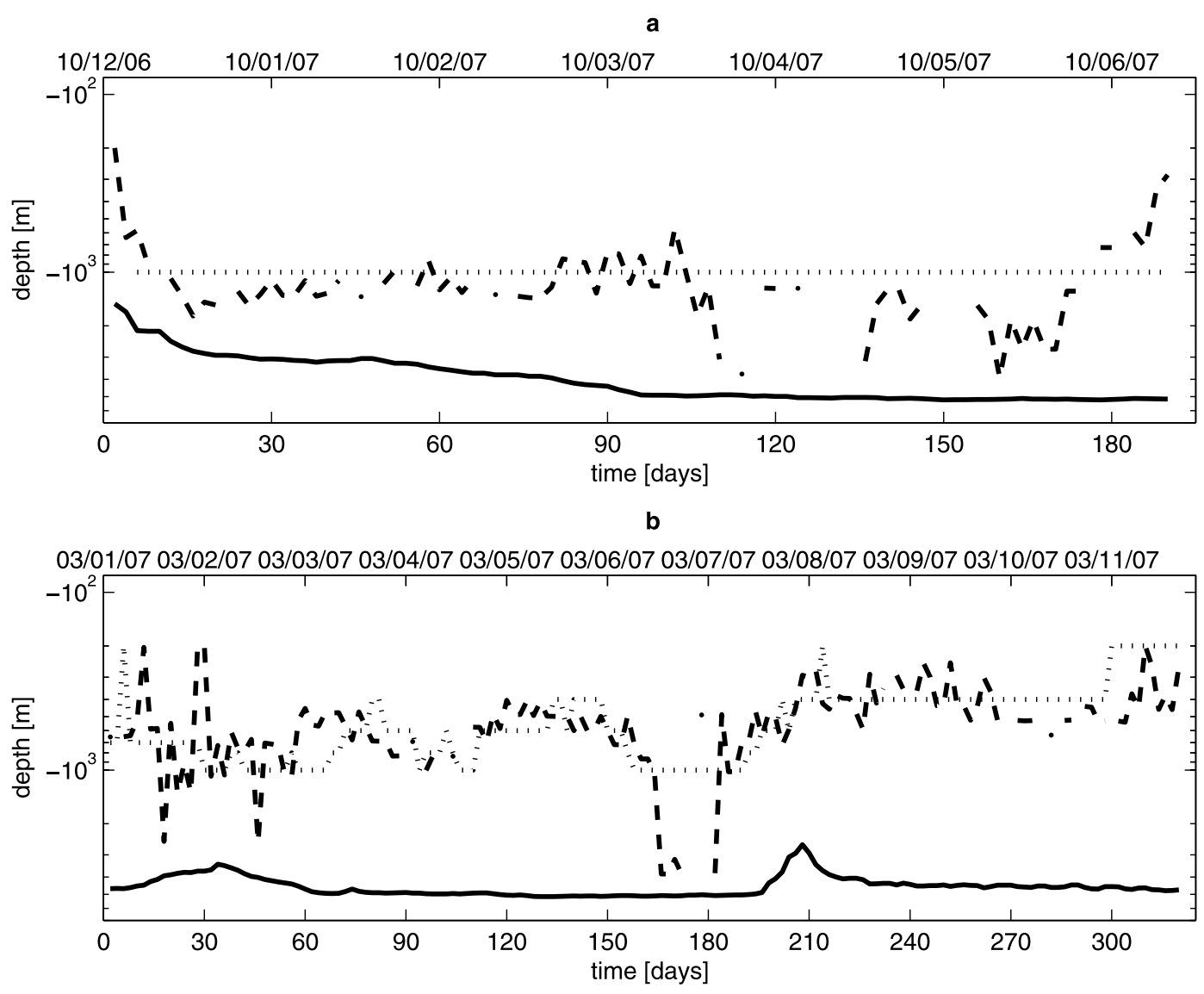

Figure 5. Vertical tracking. Time series of the deepest vertical tracking level $i z_{L}$ reached by the wavelet analysis (dotted line), the maximum depth at which Flierl's criterion can be defined (dashed line), and bathymetry below the eddy center (solid line). (a) For cyclone Panoramix and (b) anticyclone Idefix.

simulation, we observed good correlation of $z_{\text {Flierl }}$ and $i z_{L}$ with the translational velocity $v$ of the eddy, and to stop vertical tracking at $z_{\max }=-1000 \mathrm{~m}$ when $z_{\text {Flierl }}$ reaches deepest values seems realistic. Then, for cyclone Panoramix (Figure 5a), the Flierl criterion confirms that the eddy extends at least down to $1000 \mathrm{~m}$ for quite some time (from 5 to day 60). The vertical extension of anticyclone Idefix is smaller (Figure 5b), and both definitions of its maximum depth give equivalent results.

[15] In summary, at a fixed time step, the area $A_{k}$ and diameter $D_{k}$ are both diagnosed at each level $k$ and the volume $V$ taken up by each eddy can be calculated as:

$$
V=\sum_{k=1}^{i z_{L}} A_{k} \cdot \Delta z
$$

The knowledge of instantaneous velocity $v$, diameter $D$, and volume $V$ of each structure enables one to calculate an instantaneous transport and an instantaneous momentum denoted Tinst and Minst, respectively (see Appendix A and section 4).

\section{Results and Discussion}

[16] Let us, now, focus on the three anticyclones, Asterix, Idefix, and Obelix, and the cyclone, Panoramix, successfully tracked by our technique between the end of year 6 and the end of year 7 of our 11-year simulation. In slightly more than 6 months (day 10/month 11/year 6 to day 14/month $5 /$ year 7 , in southern summer and fall), Panoramix moved mainly west-southwestward and eventually turned south just before turning into a filament (Figures 1 and $4 a$ ). Tracking of Idefix for slightly less than 10 months, from day 3/month 12/year 6 to day 11/month 10/year 7 (in southern summer, fall, and winter), highlighted a northwestward motion (Figures 1 and 4b). Obelix (from day 10/month 11/year 6 to day 5/month 3/year 7) and Asterix (from day 14/month 1/year 7 to day 13/month 6/year 7) also moved along this direction (Figure 1). Such a divergence in eddy pathways between cyclones and anticyclones has been also reported from satellite and drifter data [Boebel et al., 2003; Morrow et al., 2004]. According to Morrow et al. [2004], it is induced by changes in planetary and relative vorticity on the flanks of the eddy, but other causes are possible.

[17] The time series for cyclone Panoramix (Figure 6 and Appendix A for details on the calculation of the associated error bars) show different periods in the life of the eddy. When the eddy moves over the continental slope, its translational velocity is weak, and its shape is more or less circular. Indeed, there is nearly no change in diameter and volume during this first stage. Then, the cyclone moves into the Cape Basin and starts to interact with other eddies and filaments. Before it becomes itself a filament, the successive 


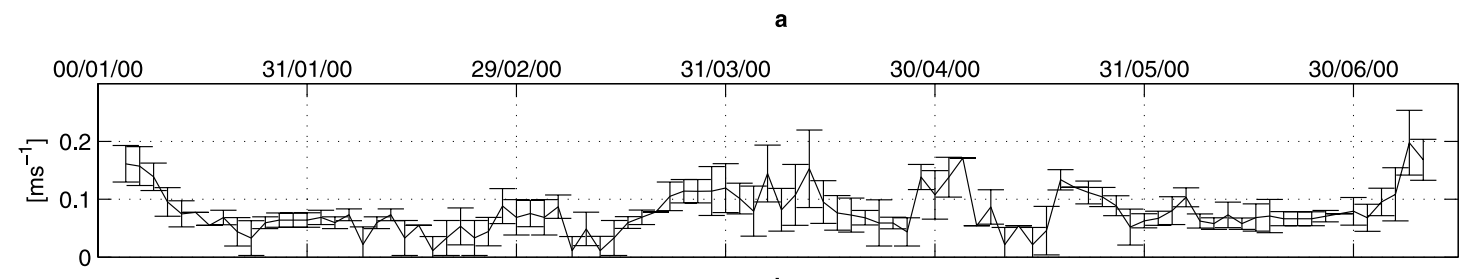

b
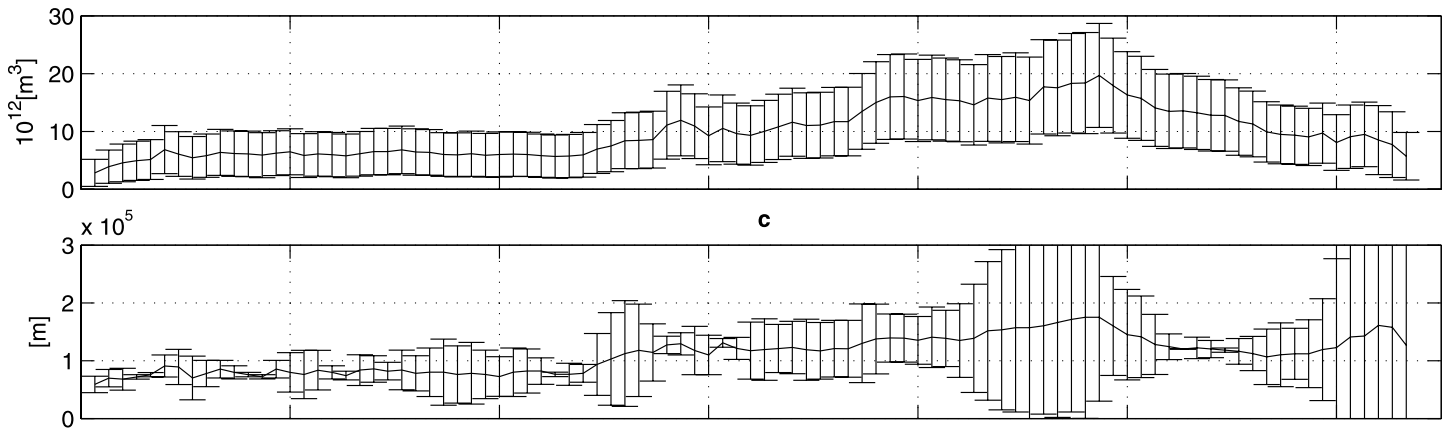

d
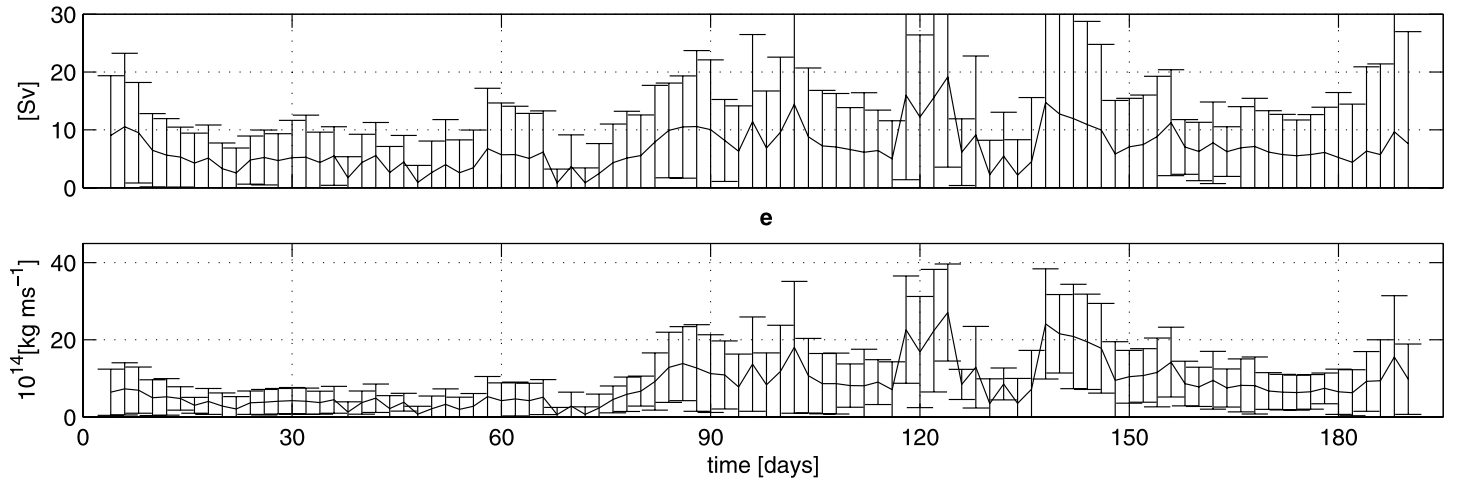

Figure 6. (a) Translational velocity, (b) volume, (c) diameter, (d) instantaneous transport, and (e) instantaneous momentum of cyclone Panoramix.

growth and reduction of its volume as well as a high variability of its diameter indicate that it incorporates and loses some mass. Its instantaneous transport and momentum are increasing both in magnitude and variability during this stage.

[18] Among the time series obtained for the three anticyclones, the Idefix one is the longest (Figure 7). Velocity, volume, and diameter show significant variability at the stage of eddy formation. Then, there is a central period over which the eddy is well structured, and its volume and diameter remain nearly unchanged as it is moving within the Cape Basin. These small variations indicate that our algorithm works fairly well for eddy identification; the eddies that do not interact with their surroundings should indeed conserve their tracer properties in time. The variation in volume and velocity between 170 and 210 days of its lifetime is caused by the crossing of the Walvis Ridge (Figure 5b). Beyond the ridge, the eddy volume is reduced and the velocity is less regular. Here large standard deviations in diameter with no correspondence with large standard deviations in volume are the signs of a shape becoming more and more stretched. The instantaneous transport and momentum show a general decline over the eddy lifetime, suggesting a loss of impetus during its northwestward journey, whereas modulations in time look mainly driven by velocity changes.

[19] Table 1 summarizes the time-averaged values of eddy parameters. The cyclone, Panoramix, and the anticyclone, Idefix, have similar translational velocities, whereas the other two anticyclones are moving faster. The difference may partly come from the shortness of the tracking of Obelix and Asterix since a short time series likely induces a bias on the calculation of average values. A comparison with previous studies suggests that our estimates of drift velocity, volume, and diameter for Cape Basin eddies are realistic. Cyclones and anticyclones tracked by van Ballegooyen et al. [1994] had drift velocities between 0.037 and $0.090 \mathrm{~ms}^{-1}$. In the work of Arhan et al. [1999], the anticyclone, R3, displays a path very close to the one we obtained for Idefix, with a mean drift velocity of $0.09 \mathrm{~ms}^{-1}$ (when averaged over 100 days). Similar values were found by Garzoli et al. [1999] who pointed out that such velocities fall within the range of previous observations [Goñi et al., 1997]. More recently, Schmid et al. [2003] observed and tracked a specific Agulhas Ring with satellite altimetry and RAFOS trajectories; the translational velocity estimated by altimetry ranged from 0.011 to $0.273 \mathrm{~ms}^{-1}$ (with an estimated error of about $0.03 \mathrm{~ms}^{-1}$ ). For some periods, these authors also found a match between drift estimates calculated from 


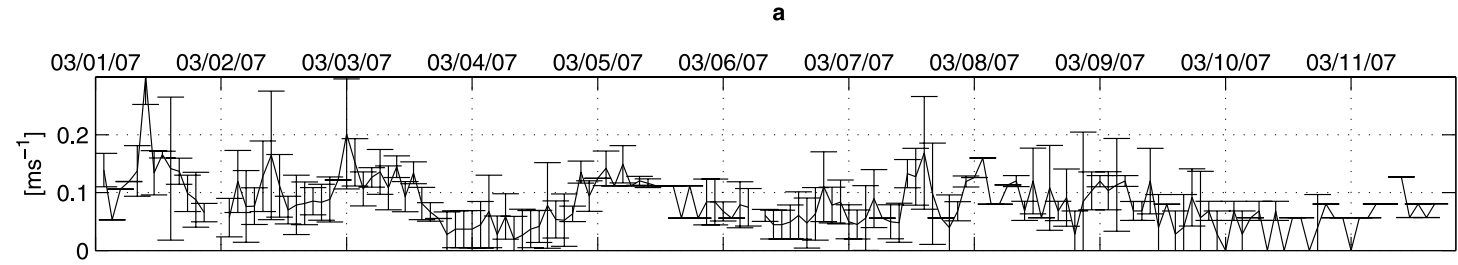

b
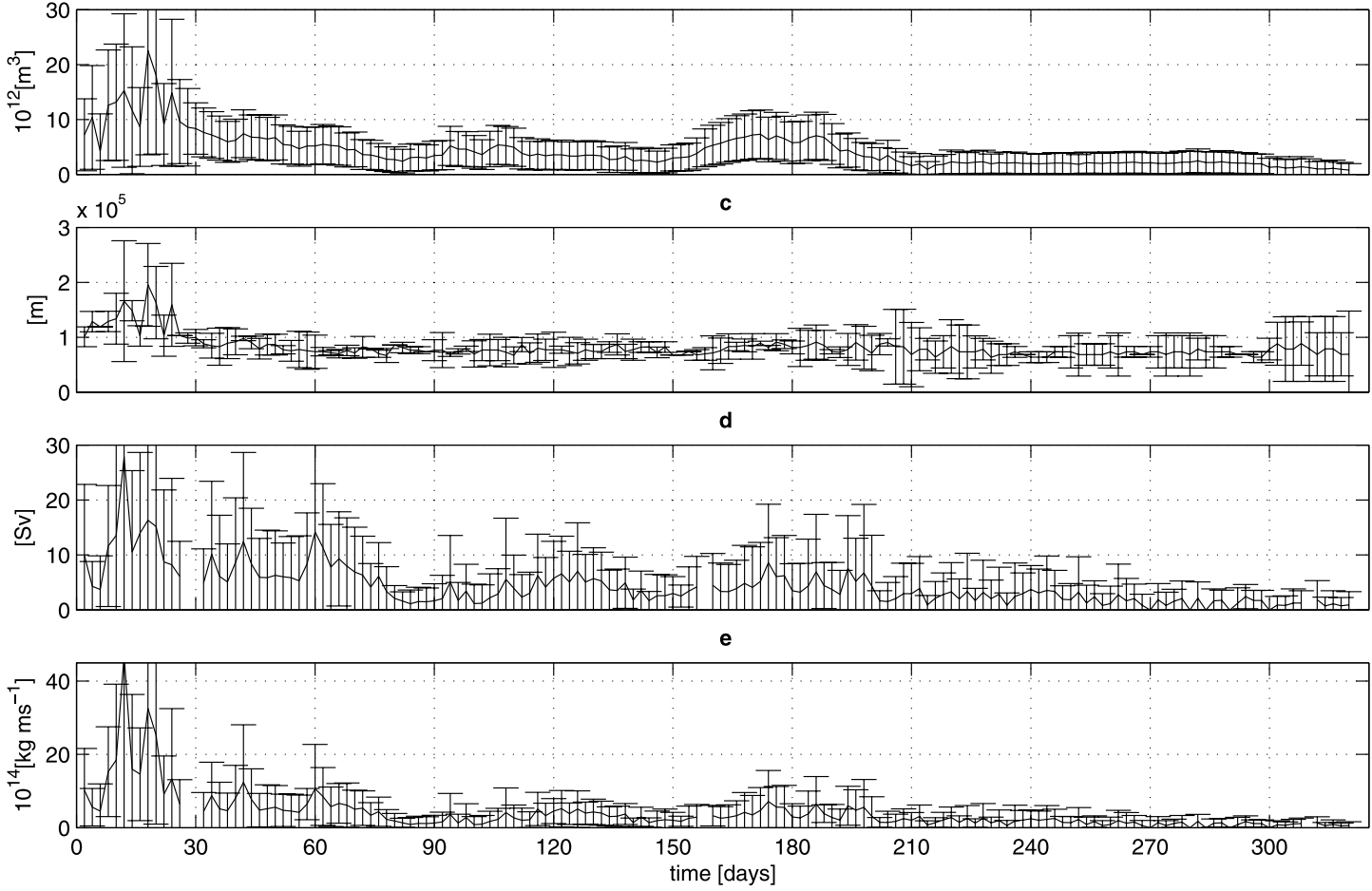

Figure 7. Same as Figure 6, but for anticyclone Idefix.

RAFOS floats and averaged values calculated from altimetry. van Aken et al. [2003] calculated drift velocities of about 0.03 and $0.10 \mathrm{~ms}^{-1}$ for two different rings. Observations reported by Boebel et al. [2003] and Morrow et al. [2004] showed a faster motion of anticyclones compared with cyclones. Our results agree with this statement, but our modeled drift velocities are about twice their estimates. In a model of the Atlantic circulation, Treguier et al. [2003] calculated the average velocity of Agulhas Rings once they had crossed Walvis Ridge and pointed out that their result $\left(0.06 \mathrm{~ms}^{-1}\right)$ was similar to velocities diagnosed by Schouten et al. [2000] and Garnier et al. [2003] from altimetry data.

[20] As regards volume and diameter, our anticyclones are, in average, smaller than observed Agulhas rings [van Aken et al., 2003, and references cited therein]. This bias is mainly attributable to the nature of the comparison. Estimates cited in literature often correspond to instantaneous or short-term averaged values, whereas our mean parameters were calculated over several months of tracking. Our recorded maximum values (omitting error bars) of $V=23,31$, and $33 \times 10^{12} \mathrm{~m}^{3}$ and $D=$ 195, 273, and $219 \mathrm{~km}$ for Idefix, Obelix, and Asterix, respectively, are in fact in fair agreement with typical observations at sea. Furthermore, our definition of eddy volume is not based on hydrological criteria as done in most previous studies (for example, the water volume above the $10^{\circ} \mathrm{C}$ isotherm), and our definitions of diameter and area apply also to noncircular eddies. Planned analyses of hydrological properties of modeled eddies will address

Table 1. Time-Averaged Eddy Parameters

\begin{tabular}{lcccc}
\hline \multicolumn{1}{c}{ Eddy Name } & PANORAMIX & IDEFIX & OBELIX & ASTERIX \\
\hline Tracking Duration (days) & 190 & 320 & 110 & 150 \\
$\bar{v}\left(\mathrm{~ms}^{-1}\right)$ & 0.079 & 0.083 & 0.127 & 0.115 \\
$\bar{V} 10^{12}\left(\mathrm{~m}^{3}\right)$ & 10 & 4 & 14 & 12 \\
$\bar{D}(\mathrm{~km})$ & 111 & 81 & 156 & 128 \\
Tinst $(\mathrm{Sv})$ & 6.8 & 4.3 & 5.7 & 5.9 \\
\hline Minst $10^{14}\left(\mathrm{~kg} \mathrm{~ms}^{-1}\right)$ & 8.2 & 4.0 & 5.3 & 6.1 \\
\hline
\end{tabular}


a more accurate comparison with observations. Nevertheless, we already point out that our estimate of the ratio between diameter and volume is in good agreement with the one found for observed eddies. Our conclusions also hold for cyclones though the data available in the literature about this topic in the Cape Basin are far less numerous. Boebel et al. [2003] found a typical diameter of $120 \mathrm{~km}$ for these structures, whereas van Ballegooyen et al. [1994] measured an initial dimension of $160 \mathrm{~km}$ for a cyclone formed near the Agulhas retroflection.

[21] Besides translational velocity, volume, and diameter, we suggest two other physical quantities that we consider to be meaningful for differentiating individual contributions to transport by coherent eddies as follows: the instantaneous transport, Tinst, and the instantaneous momentum, Minst (see Appendix A for mathematical definitions). Tinst represents the instantaneous transport induced by an eddy of a given volume crossing completely a fixed imaginary section positioned in front of it, i.e., covering a distance equal to its diameter while moving at its drift velocity. Minst accounts directly for the momentum of the eddy and is obtained by multiplying its mass by its velocity. Our definition for transport differs from the one generally used in data analysis [e.g., van Ballegooyen et al., 1994] or models [Treguier et al., 2003]. The "classical" approach calculates the individual transport by dividing the typical volume of an eddy by 1 year. Multiplying this transport by the average number of equivalent propagating structures per year gives an estimate of the mean transport achieved by the eddy field, and it can be used, for instance, to diagnose the transmission of water from the Indian to the Atlantic Ocean in the form of coherent eddies. This definition would lead to transport values of about $0.4 \mathrm{~Sv}$ for Obelix and Asterix. On the contrary, as our definition of instantaneous transport does not lie on the arbitrary definition of a reference time interval, it is appropriate for the intercomparison of individual structures because of the involvement of three main characteristics of an eddy (velocity, shape, and volume). The application of our definition to specific eddies with available data about drift velocity, volume, and diameter [e.g., van Ballegooyen et al., 1994; van Aken et al., 2003; Schmid et al., 2003] leads to values for Tinst of the same order of magnitude as our modeled eddies.

\section{Summary and Conclusions}

[22] The main goal of our study was to propose objective tools for identification and tracking of three-dimensional coherent structures. Wavelet analysis allowed us to follow eddies in space and time as long as they exist as coherent structures in the model and to evaluate their translational velocity, diameter, volume, and derived parameters.

[23] This study was carried out in a regional ocean model that accounts for eddy displacements within the Cape Basin region. This oceanic region around southern Africa is a critical water mass crossroads within the so-called warmwater route of the global overturning circulation [Gordon, 1986, 2003; Gordon et al., 1992]. Oceanic eddies are of key importance in the distribution of properties like heat and salt throughout the world ocean, and Agulhas rings are thought to play a key role in the Indo-Atlantic interocean exchange [Gordon, 1986; de Ruijter et al., 1999; Weijer et al., 1999]. The Indo-Atlantic connection appears crucial in global ocean models too [Speich et al., 2001, 2002]. Furthermore, recent studies based on observations found a highly nonlinear regime in the Cape Basin (the first Atlantic Basin to collect leakage of Agulhas water) [Boebel et al., 2003]. Turbulence is so intense in this area that it could prevent the continuous advection of Indian or South Atlantic waters [de Ruijter et al., 1999]. Indeed, in the Cape Basin, eddies of different types interact with each other and with the main retroflection of the Agulhas Current, in a context of vigorous stirring and mixing [Gordon, 2003; Boebel et al., 2003; Morrow et al., 2004].

[24] In this turbulent framework, we processed maps of modeled relative vorticity with a wavelet-based decomposition. Then, in order to capture and track the full three-dimensional envelope of each eddy, we developed an algorithm based on superimposing structures at different instants and different vertical levels. The brief presentation of our validation dealt with only a few of the numerous mesoscale structures simulated by the model. Indeed, we decided to focus mostly on two types of mesoscale vortices, i.e., (1) cyclonic eddies ejected into the open ocean from the southwestern African continental slope and (2) anticyclonic eddies present in the Cape Basin. Our tracking evidenced divergent pathways for both types with a westward and equatorward propagation at a speed within 0.08 and $0.13 \mathrm{~ms}^{-1}$ for anticyclones and a westward, but poleward propagation at $0.08 \mathrm{~ms}^{-1}$ for the studied cyclone. Both behaviors are very similar to those observed with altimetry along different subtropical eastern boundaries [Morrow et al., 2004]. Our translational velocities are slightly larger than those derived from altimetry and RAFOS floats, but the tracking criteria were not alike [van Ballegooyen et al., 1994; Boebel et al., 2003; Morrow et al., 2004]. Diameter and volume time series obtained with our analysis provide useful information on the evolution of the shape of an eddy and on the interactions with surrounding structures. Timeaveraged diameters range from 81 to $156 \mathrm{~km}$ with instantaneous values exceeding $200 \mathrm{~km}$ and time-averaged volumes range from 4 to $14 \times 10^{12} \mathrm{~m}^{3}$ with instantaneous values exceeding $30 \times 10^{12} \mathrm{~m}^{3}$, in good agreement with observational data [van Aken et al., 2003, and references cited therein]. Analyses of hydrological properties of modeled eddies will be necessary for a more thorough comparison. Then, besides translational velocity, volume, and diameter, we suggest the calculation of two derived parameters that prove appropriate for the intercomparison of individual structures as follows: the instantaneous transport and the instantaneous momentum.

[25] Tracking techniques based on the calculation of Lagrangian trajectories also exist, as shown for instance by a recent analysis of the same numerical simulation [Doglioli et al., 2006]. Such Lagrangian computations coupled with the wavelet-based definition of each eddy volume will be used in a future paper to calculate the remote origins and fates of the water carried by each structure. Heat and fresh water transport estimates will also be derived for each type of eddy. This will allow the evaluation (in models) of the relevance of the ocean off South Africa in the organization of the return branch of the 
global thermohaline circulation. We plan to evaluate accurately the net exchanges across the Cape Basin in order to gain more insight into the complex role of the mesoscale processes affecting the origin and fate of water masses.

[26] Note added in proof. It has been brought to our attention that Farge et al. [1992] have first proposed the idea of wavelet packet decomposition to extract coherent structures in simulation of turbulence.

\section{Appendix A: Definitions}

[27] Let us define the instantaneous mass transport of a coherent eddy as the ratio between the eddy volume $V$ and the time $\Delta t$ needed to cross entirely a fixed section perpendicular to the direction of propagation of the eddy center:

$$
\text { Tinst }=V \cdot \Delta t^{-1} \text {. }
$$

Assuming that the time interval is $\Delta t=D \cdot v^{-1}$ where $D$ is the eddy diameter and $v$ is the velocity of the eddy center, the transport is estimated as:

$$
\text { Tinst }=v \cdot V \cdot D^{-1} \text {. }
$$

In our calculations,

$$
v \equiv v(t)=\frac{1}{i z_{L}} \sum_{k=1}^{i z_{L}} v_{k}
$$

is the vertical average of the velocity of the eddy center as computed for each $z$ layer with a backward difference scheme involving successive positions. The relative error $v_{\text {err }} \equiv v_{\text {err }}(t)$ made on velocity is estimated as:

$$
v_{\mathrm{err}}=\frac{\sigma_{z}(v)}{v},
$$

where $\sigma_{z}$ is the standard deviation of the distribution along the vertical axis.

[28] As described above, our analysis gives the eddy volume at each time step. Our estimate of the relative error $V_{\text {err }} \equiv V_{\text {err }}(t)$ on the volume calculation is

$$
V_{\mathrm{err}}(t)=\frac{\Delta z \pi\left(\frac{D}{2}\right)^{2}}{V}+\frac{4 \Delta x \Delta z \sum_{k=1}^{i z_{L}} A_{k} D_{k}^{-1}}{V}
$$

that is the sum of errors due to the vertical (step $\Delta z$ ) and horizontal (step $\Delta x$ ) discrete representations of the eddy. The first term on the right-hand side is the volume of the cylinder that the method may neglect at the base of the eddy. The second term is the approximate volume of a cylindrical ring neglected or taken by mistake around the eddy whose area $A_{k}$ and diameter $D_{k}$ are diagnosed at each level $k$.

[29] Let us define the diameter $D$ as the mean between the zonal $\left(D^{\mathrm{EW}}\right)$ and the meridional $\left(D^{\mathrm{NS}}\right)$ cords that intercept each eddy center with both endpoints on the edge of the structure. Then, by repeating this average at each level $k$, the reference diameter used in $\mathrm{A} 2$ is:

$$
D=\frac{1}{2 i z_{L}} \sum_{k=1}^{i z_{L}}\left(D_{k}^{\mathrm{EW}}+D_{k}^{\mathrm{NS}}\right) .
$$

[30] For stretched eddies in rotation, the relative error made on the calculation of $D$ with $\mathrm{A} 5$ is estimated as:

$$
D_{\text {err }}=\frac{1}{i z_{L}} \frac{\sum_{k=1}^{i z_{L}}\left|D_{k}^{\mathrm{EW}}-D_{k}^{\mathrm{NS}}\right|}{D} .
$$

[31] The relative error on our transport estimate is the sum of the errors defined in A3, A4 and A5:

$$
\text { Tinst }_{\mathrm{err}}=v_{\mathrm{err}}+V_{\mathrm{err}}+D_{\mathrm{err}} \text {. }
$$

[32] The mean transport $\overline{\text { Tinst }}$ is the time average of Tinst. Equivalently, we introduce the instantaneous momentum (and associated error) of a coherent structure as the product of its instantaneous velocity and volume. Ignoring density variations within the structure and thus using $\rho_{0}=$ $1020 \mathrm{~kg} / \mathrm{m}^{3}$ lead to:

$$
\text { Minst }=\rho_{0} \cdot V \cdot v
$$

and

$$
\text { Minst }_{\mathrm{err}}=v_{\mathrm{err}}+V_{\mathrm{err}} \text {. }
$$

Finally, the mean momentum, $\overline{\text { Minst, }}$ is the time average of Minst.

[33] Acknowledgments. The authors wish to thank Michel Arhan, Xavier Carton, Steven Herbette, Guillaume Roullet, and Anne-Marie Treguier for the enlightening discussions about eddy dynamics, and Marie-Paule Friocourt for her assistance in correcting the manuscript. A. M. Doglioli is supported by SHOM under contract number CA 2003/ 03/CMO (Contact: Alain Serpette). This study is also a contribution to InterUp, a project funded by the French LEFE-IDAO program (Les Enveloppes Fluides et l'Environnement, Interactions et Dynamique de l'Océan et de l'Atmosphère), formerly PATOM (Programme National Atmosphère et Océan à Multi-échelles).

\section{References}

Arhan, M., H. Mercier, and J. R. Lutjeharms (1999), The disparate evolution of three Agulhas rings in the South Atlantic Ocean, J. Geophys. Res., 104(C9), 20,987-21,005.

Basdevant, C., and T. Philipovitch (1994), On the validity of the "Weiss criterion" in two-dimensional turbulence, Physica D, 113, 17-30.

Beckmann, A., and D. Haidvogel (1993), Numerical simulation of flow around a tall isolated seamount: Part 1. Problem formulation and model accuracy, J. Phys. Oceanogr., 23(8), 1736-1753.

Blanke, B., S. Speich, A. Bentamy, C. Roy, and B. Sow (2005), Modeling the structure and variability of the southern Benguela upwelling using QuikSCAT wind forcing, J. Geophys. Res., 110, C07018, doi:10.1029/ 2004JC002529.

Boebel, O., J. Lutjeharms, C. Schmid, W. Zenk, T. Rossby, and C. Barron (2003), The cape cauldron: a regime of turbulent inter-ocean exchange, Deep Sea Res. Part II, 50, 57-86.

Capet, X., P. Marchesiello, and J. McWilliams (2004), Upwelling response to coastal wind profiles, Geophys. Res. Lett., 31, L13311, doi:10.1029/ 2004GL020123.

Chelton, D. B., R. A. deSzoeke, M. G. Schlax, K. El Naggar, and N. Siwertz (1998), Geographical variability of the first-baroclinic Rossby radius of deformation, J. Phys. Oceanogr., 28, 433-460.

Coifman, R. R., and M. V. Wickerhauser (1992), Entropy based algorithms for best basis selection, IEEE Trans. Inf. Theory, 32, 712-718.

Da Silva, A. M., C. C. Young, and S. Levitus (1994), Atlas of surface marine data 1994, vol. 1, algorithms and procedures, Tech. rep., U.S Department of Commerce, NOAA, Washington, DC.

Daubechies, I. (1988), Orthonormal basis of compactly supported wavelets, Commun. Pure Appl. Math., 909-996.

Daubechies, I. (1992), Ten Lectures on Wavelets, 357 pp., Society for Industrial and Applied MathematicsPhiladelphia, PA.

de Ruijter, W. P. M., A. Biastoch, S. S. Drijfhout, J. R. E. Lutjeharms, R. P. Matano, T. Pichevin, P. J. van Leeuwen, and W. Weijer (1999), Indian-Atlantic interocean exchange: Dynamics, estimation and impact, J. Geophys. Res., 104(C9), 20,885-20,910. 
Doglioli, A. M., M. Veneziani, B. Blanke, S. Speich, and A. Griffa (2006), A Lagrangian analysis of the Indian-Atlantic interocean exchange in a regional model, Geophys. Res. Lett., 33, L14611, doi:10.1029/ 2006GL026498.

Donners, J., S. S. Drijfhout, and A. Coward (2004), Impact of cooling on the water mass exchange of Agulhas rings in a high resolution ocean model, Geophys. Res. Lett., 31, L16312, doi:10.1029/2004GL020644.

Elhmaidi, D., A. Provenzale, and A. Babiano (1993), Elementary topology of two-dimensional turbulence from a Lagrangian viewpoint and singleparticle, J. Fluid Mech., 257, 533-558.

Farge, M., E. Goirand, Y. Meyer, F. Pascal, and M. V. Wickerhauser (1992), Improved predictability of two-dimensional turbulent flows using wavelet packet compression, Fluid Dyn. Res., 10, 229-250.

Flierl, G. R. (1981), Particle motions in large-amplitude wave fields, Geophys. Astrophys. Fluid Dyn., 18, 39-74.

Garnier, E., J. Verron, and B. Barnier (2003), Variability of the South Atlantic upper ocean circulation: a data assimilation experiment with 5 years of TOPEX/POSEIDON altimeter observations, Int. J. Remote Sens., 24(5), 911-934.

Garzoli, S. L., and G. J. Goñi (2000), Combining altimeter observations and oceanographic data for ocean circulation and climate studies, in Satellite, Oceanography and Society, edited by D. Halpern, chap. 5, pp. 79-97, Elsevier, New York.

Garzoli, S. L., P. L. Richardson, C. D. Rae, D. M. Fratantoni, G. J. Goñi, and A. J. Roubicek (1999), Three Agulhas rings observed during the Benguela current experiment, J. Geophys. Res., 104(C9), 20,97120,985 .

Goñi, G. J., S. L. Garzoli, A. J. Roubicek, D. B. Olson, and O. B. Brown (1997), Agulhas ring dynamics from TOPEX/POSEIDON satellite altimeter data, J. Mar. Res., 55, 861-883.

Gordon, A. L. (1986), Interocean exchange of thermocline water, J. Geophys. Res., 91, 5037-5046.

Gordon, A. L. (2003), The brawniest retroflection, Nature, 421(6926), 904-905.

Gordon, A. L., R. F. Weiss, W. M. Smethie, and M. J. Warner (1992), Thermocline and intermediate water communication between the South Atlantic and Indian Oceans, J. Geophys. Res., 97, 7223-7240.

Jameson, L., and T. Miyama (2000), Wavelet analysis and ocean modeling: A dynamically adaptive numerical method "WOFD-AHO", Mon. Weather Rev., 128, 1536-1548.

Liu, W. T., W. Tang, and P. S. Polito (1998), NASA scatterometer provides global ocean-surface wind fields with more structures than numerical weather prediction, Geophys. Res. Lett., 25(6), 761-764, doi:10.1029/ 98GL00544.

Luo, J., and L. Jameson (2002), A wavelet-based technique for identifying, labeling, and tracking of ocean eddies, J. Atmos. Oceanic Technol., 19(3), $381-390$

Lutjeharms, J. R. E., O. Boebel, and H. T. Rossby (2003), Agulhas cyclones, Deep Sea Res. Part II, 50, 13-34.

Marchesiello, P. M., J. C. McWilliams, and A. Shchepetkin (2001), Open boundary condition for long-term integration of regional oceanic models, Ocean Modell. 3, 1-21.

McWilliams, J. C. (1984), The emergence of isolated coherent vortices in turbulent flow, J. Fluid Mech., 146, 21-43.

Morrow, R., F. Birol, D. Griffin, and J. Sudre (2004), Divergent pathways of cyclonic and anti-cyclonic ocean eddies, Geophys. Res. Lett., 31, L24311, doi:10.1029/2004GL020974.

Okubo, A. (1970), Horizontal dispersion of floatable particles in the vicinity of velocity singularities such as convergences, Deep Sea Res., 17, 445454.

Penven, P., J. R. E. Lutjeharms, P. Marchesiello, C. Roy, and S. J. Weeks (2001), Generation of cyclonic eddies by the Agulhas Current in the lee of the Agulhas Bank, Geophys. Res. Lett., 27(6), 1055-1058.
Penven, P., V. Echevin, J. Pasapera, F. Colas, and J. Tam (2005), Average circulation, seasonal cycle, and mesoscale dynamics of the Peru Current System: A modeling approach, J. Geophys. Res., 110, C10021, doi:10.1029/2005JC002945.

Richardson, P. L., J. R. E. Lutjeharms, and O. Boebel (2003), Introduction to the "Inter-ocean exchange around southern Africa", Deep Sea Res. Part II, 50, 1-12.

Ruppert-Felsot, J. E., O. Praud, E. Sharon, and H. L. Swinney (2005), Extraction of coherent structures in a rotating turbulent flow experiment, Phys. Rev. E, 72(016311).

Schmid, C., O. Boebel, W. Zenk, J. R. E. Lutjeharms, S. L. Garzoli, P. L. Richardson, and C. Barron (2003), Early evolution of an Agulhas Ring, Deep Sea Res. Part II, 50(1), 141-166.

Schouten, M., W. de Ruijter, and P. van Leeuwen (2000), Translation, decay and splitting of Agulhas rings in the southeastern Atlantic Ocean, J. Geophys. Res., 105, 21,913-21,925.

Shchepetkin, A. F., and J. C. McWilliams (2003), A method for computing horizontal pressure-gradient force in an oceanic model with nonaligned vertical coordinate, J. Geophys. Res., 108(C3), 3090, doi:10.1029/ 2001JC001047.

Shchepetkin, A. F., and J. C. McWilliams (2005), The regional oceanic modeling system (ROMS): A split-explicit, free-surface, topographyfollowing-coordinate oceanic model, Ocean Modell., 9, 347-404.

Siegel, A., and J. B. Weiss (1997), A wavelet-packet census algorithm for calculating vortex statistics, Phys. Fluids, 9, 1988-1999.

Smith, W. H. F., and D. T. Sandwell (1997), Global sea floor topography from satellite altimetry and ship depth soundings, Science, 227, 19561962.

Speich, S., B. Blanke, and G. Madec (2001), Warm and cold water paths of a O.G.C.M. thermohaline conveyor belt, Geophys. Res. Lett., 28(2), $311-314$.

Speich, S., B. Blanke, P. de Vries, S. Drijfhout, K. Döös, A. Ganachaud, and R. Marsh (2002), Tasman leakage: A new route in the global ocean conveyor belt, Geophys. Res. Lett., 29(10), 1416, doi:10.1029/2001GL014586.

Treguier, A., O. Boebel, B. Barnier, and G. Madec (2003), Agulhas eddy fluxes in a $1 / 6^{\circ}$ Atlantic model, Deep Sea Res. Part II, 50, 119-139.

van Aken, H. M., A. K. van Veldhoven, C. Vetha, W. P. M. de Ruijter, P. J. van Leeuwen, S. S. Drijfhout, C. P. Whittled, and M. Rouault (2003) Observations of a young Agulhas ring, Astrid, during MARE in March 2000, Deep Sea Res. Part II, 50, 167-195.

van Ballegooyen, R. C., M. L. Gründlingh, and J. R. E. Lutjeharms (1994), Eddy fluxes of heat and salt from the southwest Indian Ocean into the southeast Atlantic Ocean: A case study, J. Geophys. Res., 99(C7), $14,053-14,070$

Wang, D. P. (1993), Model of frontogenesis: Subduction and upwelling, J. Mar. Res., 51, 497-513.

Weijer, W., W. P. M. de Ruijter, H. A. Dijkstra, and P. J. van Leeuwen (1999), Impact of interbasin exchange on the Atlantic overturning circulation, J. Phys. Oceanogr., 29, 2266-2284.

Weiss, J. (1991), The dynamics of enstrophy transfer in two-dimensional hydrodynamics, Physica D, 48, 273-294.

Wickerhauser, M. V. (1994), Adapted Wavelet Analysis from Theory to Software, xii +486 pp., AK Peters, Ltd., Wellesley, Mass.

B. Blanke, A. M. Doglioli, and S. Speich, Laboratoire d'Océanographie et de Biogéochimie, UMR 6535 CNRS/Université de la Méditerranée, OSU/Centre d'Océanologie de Marseille, Campus de Luminy case 901, 13288, Marseille Cedex 9, France. (doglioli@univmed.fr)

G. Lapeyre, Laboratoire de Météorologie Dynamique IPSL, École Normale Supérieure/CNRS, Paris, France. 